\title{
BUFFER STOCKS ARE BETTER STABILIZERS THAN QUOTAS
}

\author{
Edward TOWER* \\ Duke University, Durham, NC 27706, USA \\ Received October 1979
}

\begin{abstract}
Michael Pelcovits $(1979$, p. 307) recently showed that with an unstable foreign excess supply curve, either a fixed quota or a buffer stock program with a fixed tariff can be used to stabilize domestic price at a given level. and both policies 'will have the same effect on social welfare [so ...t] the choice between [the two...] must then be made on the basis of administrative cost and feasibility'. However, he reached his conclusion by ranking the two policies on the basis of domestic welfare, and in this note we demonstrate with his same model that on the basis of foreign welfare the buffer stock is better than the quota. Thus, world weffare is higher under the buffer stock than under the quota.
\end{abstract}

\section{Introduction}

Pelcovits (1979) considers a country which wishes to stabilize the internal price of widgets, some of which it imports. Referring to fig. 1, the instability arises from vertical and parallel shifts of the linear foreign excess supply curve, which takes the position of $E S_{1}$ in oda periods and $E S_{2}$ in even ones ${ }^{1}$ and has a slope of $b>0$. If the home country imposes an ad valorem tariff of $t$, the tariff-distorted excess supply curves which correspond to $E S_{1}$ and $E S_{2}$ are $E S_{1}^{\prime}$ and $E S_{2}^{\prime}$, respectively. Both have a slope of $(1+t) b$ and the extension of each to the left of the vertical axis shares its horizontal intercept, $Z_{1}$ or $Z_{2}$, with the extension of the corresponding $E S$ curve. Let $P_{U}$ be the price at which the demand curve bisects the horizontal line connecting $E S_{1}^{\prime}$ and $E S_{2}^{\prime}$. Furthermore, let $M_{1}, M_{2}$, and $\bar{Q}$ be the horizontal coordinates of the intersections with price $P_{U}$ of $E S_{1}^{\prime}, E S_{2}^{\prime}$, and domestic excess demand, $E D_{M}$, at $m_{1}, m_{2}$, and $q$, respectively. Thus, if a tariff, $t$, is imposed and the government uses buffer stocks to stabilize domestic price at $P_{V}$ it will accumulate $\bar{Q} M_{1}$ widgets in the odd periods and decumulate the same quantity $M_{2} \bar{Q}$ in the even periods, because by construction $\bar{Q} M_{1}=M_{2} \bar{Q}$.

The area below the excess supply curve which represents the foreign cost of producing for export plus the opportunity cost of foreign consumption

-Currently a Visiting Professor at Simon Fraser University, Burnaby, Canada.

${ }^{1}$ Actually, all that is needed for our analysis to hold is that the probability distribution of the vertical intercept be symmetric. 


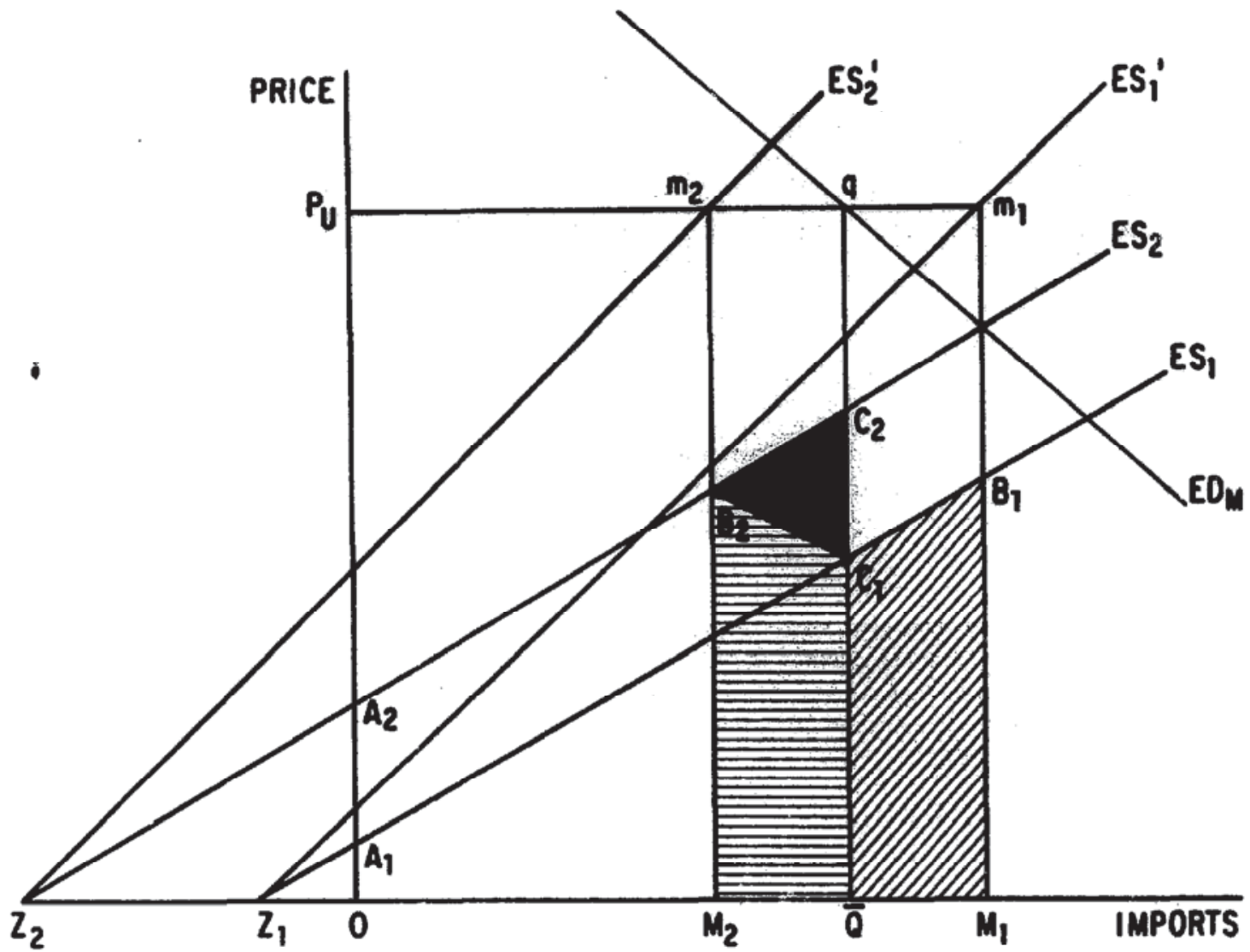

Fig. 1

forgone on the exports is given by $A_{1} B_{1} M_{1} O$ in the odd periods and by $\mathrm{A}_{2} \mathrm{~B}_{2} \mathrm{M}_{2} \mathrm{O}$ in the even periods. On the other hand if a quota is used to stabilize imports at $\bar{Q}$, this cost will be $A_{1} C_{1} \bar{Q} O$ in the odd periods and $A_{2} C_{2} \overline{Q O}$ in the even. Thus, the excess cost under the quota above that under the tariff-cum-buffer scheme over one odd and one even period is the solid triangle plus the horizontally slashed area minus the diagonally slashed area. Since $m_{1} Z_{1} B_{1}$ and $m_{2} Z_{2} B_{2}$ are congruent triangles with their corresponding sides parallel, $B_{1}$ and $B_{2}$ will have the same vertical coordinates. Thus, the cost under the quota is higher by the solidly shaded area. This qualitative conclusion is obvious, because under the tariff-cum-buffer scheme the marginal cost of production is equalized in the two periods whereas under the quota it is not.

\section{Conclusion}

Since Pelcovits proves that foreign revenues are the same under both schemes, it is clear that foreign welfare is higher with the buffer scheme than with the quota. Thus, if the domestic government can induce the foreign one 
to share any of this surplus explicitly, or implicitly by taking an easier bargaining position on some extraneous issue between them, or if the domestic government is favorably disposed toward foreigners, it should use the tariff-cum-buffer scheme in preference to the quota.

\section{Reference}

Pelcovits, M.D., 1979, The equivalence of quotas and buffer stocks as alternative stabilization policies, Journal of International Economics 9, 303-307. 